Int. J. Environ. Sci. Tech., 4 (1): 1-9, 2007

ISSN: $1735-1472$

(C) Winter 2007, IRSEN, CEERS, IAU

\title{
Contamination by organochlorine pesticides from rivers
}

\author{
${ }^{1 *}$ S. T. Imo, ${ }^{1}$ M. A. Sheikh, ${ }^{1}$ E. Hirosawa, ${ }^{2}$ T. Oomori, ${ }^{3}$ F. Tamaki \\ ${ }^{1}$ Graduate School of Engineering and Science, University of the Ryukyus, Senbaru 1, Nishihara-cho, Okinawa, Japan \\ ${ }^{2}$ Department of Chemistry, Faculty of Science, University of the Ryukyus, Senbaru 1, Nishihara-cho, Okinawa, Japan \\ ${ }^{3}$ Okinawa Prefectural Institute of Health and Environment, Water Pollution Section, 2085 Ozato, Ozato-son, \\ Okinawa, Japan
}

Received 11 September 2006; revised 26 October 2006; accepted 28 November 2006; available online 1 January 2007

\begin{abstract}
The contamination of organochlorine pesticides (OCPs) from the selected rivers in Okinawa Island was investigated to estimate the current status of pollution in water, plants and surface sediments in these rivers. The Aja River, Asato River, Houtoku River, Kokuba River and Okukubi River were selected for this study. The concentration of the total pesticides were in the range of $0.94-231.8 \mathrm{ng} / \mathrm{L}$ in river water, $0.006-191.6 \mathrm{ng} / \mathrm{L}$ dry weight in river sediments and 0.001-55.8 ng/L dry weight in plants. Among the OCPs, $\Sigma$ HCB of $\alpha$-BHC, $\beta$-BHC and Aldrin were the common detected compounds in river water. The $\alpha$-BHC, Aldrin and Dieldrin were the most frequent detected compounds in river sediments and $\alpha$-BHC and Dieldrin were the common OCPs detected in plants. Aldrin, Dieldrin and $\Sigma$ HCB were in abundance. Various contamination patterns between the selected river water, sediments and plants were observed. Aja River, Asato River and Houtoku River were contaminated with $\alpha, \beta, \delta, \gamma$ - BHC, Aldrin and Dieldrin (water and sediments) whereas the main OCPs in Kokuba River and Okukubi River were Dieldrin (plants) The OCPs levels in all rivers were generally below guideline values in Japan, but some sites displayed levels which exceeded the EC and WHO Standards for Aldrin, Dieldrin and $\alpha, \beta$-BHC.
\end{abstract}

Key words: Contamination, organochlorine pesticides, Okinawa Island

\section{INTRODUCTION}

Contamination of the environment by organochlorine pesticides (OCPs) is of a great concern. They are noted for their persistence, bioaccumulative and toxicity characteristics in the environment. These compounds have been or continue to be used in large quantities. Although it is undisputed that OCPs are essential in modern agriculture, there is growing concern about the toxic side effects of these chemicals that pose a potential threat to the environment. Due to their widespread use, these compounds are detected by determination of their residues in various environmental matrices such as water, air, sediments, soil, vegetation and biota (Kang, et al., 2001). An organochlorine pesticides (OCPs) residue reaches the aquatic environment through direct run-off, leaching, equipment washing and careless disposal of empty containers etc. (Miliadis, et al., 1993). These OCPs including the group of DDT (dichloro-phenyltricholoroethane), isomers of BHC (hexachlorobenzene), aldrin, dieldrin, endrin, chlordane, toxaphene, endrin, *Corresponding author, Email: k058557@eve.u-ryukyu.ac.jp
Tel/Fax: +81 09057428098 heptachlor, heptachlor epoxide, Methoxychlor and HCH (hexacyclochlorobenzene) Some third world countries are still using chlorinated pesticides because of their low cost versatility in industry, agriculture and public health (Tanabe, et al., 1994). In Vietnam, the prohibition of these substances was first issued in 1993, but some studies showed that DDTs were detected in their highest concentration (Hung, et al., 2002). In Taiwan, a recent study showed that there still exist a variety of OCPs residues in the rivers which DDT and HCHs were the dominant OCPS compounds (Doong, et al., 2003). The River Wuchuan, China, OCPs were found in various environmental matrices (Zhang, et al., 2002). Even developed countries including Germany, the prohibition of OCPs was effective 25 years ago, but DDTs were still detected in canal waters (Hung, et al., 2002). In USA, Europe (Germany, Russia), Africa (Egypt) as well as Asia (China), the presence of OCPs in surface waters, sediments, biota and vegetations have been investigated in detail (Castilho, et al., 2000; Jiang, et al., 2000; Zhulidov, et al., 2000; Samia, et al., 2000). In Japan, the using of these OCPS has 
been prohibited in the field in the 1970-1980 (Nakai, et al., 2004). However, recent studies reconfirmed that OCPs residues are still environmentally persistence in nature (Nakamura, et al., 2004). The Rivers in Okinawa Island are polluted from various sources (Okinawa Prefecture Basic Plan, 2002). River improvements focused only on flood control have also disputed the river ecosystems. Aja River, Asato River and Houtoku River are surrounded by residential areas. Okukubi River runs through the Okukubi wetland. The Okukubi estuary is intensively cultivated and the wastewater from agricultural activities is accumulated and then discharged to the estuary. The Kokuba River runs through Manko Estuary which is another wetland in Okinawa. Kokuba River is located near to Naha (cacpital city of Okinawa Island) commercial services and naval port for US Military and Japanese Coastguard. Most of these rivers provide habitat for the native fish such as Killifish (Oryzias latipes) and Paradise fish (Macropodus opercularis) which are now significantly thinning (Okinawa Prefecture Basic Plan, 2002). The objective of this study was to determine the contamination level of OCPs in water, plants and sediments from selected rivers in Okinawa Island by determining the possible sources and to elucidate the contamination status of OCPs in these rivers.

\section{MATERIALS AND METHODS}

Sampling and sample processing

Samples from Aja River (AJ), Asato River (AS), Houtoku River (Ho), Kokuba River (Ko) and Okukubi (Oku) were collected in October 2005-June 2006. The location of the sampling stations is shown in Fig. 1. Eight sampling stations have been established along each river (upstream and estuary) and four samples were collected from each station. Water samples were taken using 2 L glass bottles. The vials were precleaned with soap, rinsing with ultrapure water (Milli Q plus 185) then with acetone (Kanto Chemical Co. Inc) and placed them in the oven at $150{ }^{\circ} \mathrm{C}$ for $1.5 \mathrm{~h}$. Water samples were pre-filtered through $0.45 \mu \mathrm{m}$ fiber glass filters (WHATMAN) to remove debris and suspended materials. Samples were preserved by adding $5 \mathrm{~mL}$ of concentrated $\mathrm{H}_{2} \mathrm{SO}_{4}$ to avoid biological activity. The preservative did not show any interference with OCP compounds. Surface sediment samples were collected with a grab sampler. The upper $15 \mathrm{~cm}$ of the surface sediments were carefully removed and stored in $1 \mathrm{~L}$ glass vials. Plant samples were collected using plant cutter and stainless steel tweezers, stored in 1 L glass vials. All samples (water, surface sediments, plant) were transported to the laboratory and were stored at $-20^{\circ} \mathrm{C}$ until extraction.

\section{Sample extraction}

Pre-filtered water samples (1L) were processed using a Solid Phase Extraction (SPE) technique. Methanol (Kanto Chemical Co. Inc) was added to the water sample and Surrogate Standard (4, 4'-Dibromophenyl) (5 $\mathrm{g} / \mathrm{L})$ were added to all samples (water, surface sediments, plant) to allow better extraction (Golfinopoulos, et al., 2002). Prior to the extractions, the Agilent SPE cartridges (ENVI-18) were first conditioned with $5 \mathrm{~mL}$ of Methanol followed by $5 \mathrm{~mL}$ of acetone and $5 \mathrm{~mL}$ of Milli Q water. The water samples (1L) were passed through the cartridges at a flow rate less than $10 \mathrm{~mL} / \mathrm{min}$. The cartridges were not allowed to become dry as recommended by the Agilent SPE manual. The samples were well mixed and allowed to flow through the cartridges with a flow rate of $6-0 \mathrm{~mL} / \mathrm{min}$. Following extraction, the cartridges were eluted with $5 \mathrm{~mL}$ of acetone and $5 \mathrm{~mL}$ of Milli Q water and then centrifuged at $1000-1500 \mathrm{rpm}$ for $5 \mathrm{~min}$. The cartridges were eluted with $3 \mathrm{~mL}$ of acetone and the dried extracts were collected and reduced to a volume of $2 \mathrm{~mL}$ under gentle blow of nitrogen. Surface sediment and plant samples were extracted by ultrasonication. Prior to extraction, surface sediments were freeze dried, homogenized with a stainless spatula, and then mixed with anhydrous $\mathrm{Na}_{2} \mathrm{SO}_{4}$. The samples were extracted twice with $10 \mathrm{~mL}$ Dichloromethane, followed by centrifugation for $15 \mathrm{~min}$ and then evaporated on a rotary evaporator near to dryness. The residues for determining OCPs were dissolved in $1 \mathrm{~mL}$ of Hexane. Plant samples were resized into small pieces, and mixed it with $50 \mathrm{~mL}$ of acetonitrile. The samples were homogenized for 5 minutes after adding $10 \mathrm{~g} \mathrm{NaCl}$ and $\mathrm{Na}_{2} \mathrm{SO}_{4}$. Followed by centrifugation for 5 minutes and then evaporates under clean nitrogen with water bath at $35^{\circ} \mathrm{C}$. Extraction was processed using ENVI Carb SPE tubes. The elution of OCPs with acetonitrile: toluene (3:1). The samples were concentrated under rotary evaporator. A $1 \mathrm{~mL}$ of Internal Standard (Pentachloronitrobenzene, $10 \mu \mathrm{g} / \mathrm{L}$ ) was added to all sample vials before GC analysis.

\section{Sample analyses}

The OCPs residues were analyzed by Hewlett 
Packard Gas Chromatograph 6890 Plus, with a microcell electron capture detector ( $\mu \mathrm{ECD}$ ), an autosampler and Chem Station software. A $30 \mathrm{~m}$ x $0.32 \mathrm{~mm}$ i.d x 0.25 $\mu \mathrm{m}$ film thickness fused silica capillary column HP 1 was used for the chromatographic separation of pesticides. The oven temperature program was programmed from $80^{\circ} \mathrm{C}$ to $190^{\circ} \mathrm{C}$ at $25^{\circ} \mathrm{C} / \mathrm{min}, 190-280$ ${ }^{\circ} \mathrm{C}$ at $5^{\circ} \mathrm{C} / \mathrm{min}$, then $280-300^{\circ} \mathrm{C}$ at $25^{\circ} \mathrm{C} / \mathrm{min}$ and held at $300{ }^{\circ} \mathrm{C}$ for $2 \mathrm{~min}$. The OCPs compounds were confirmed using GC-MS. Chlorinated Pesticides Standards (19 compounds each at $500 \mu \mathrm{g} / \mathrm{L}$ ) and Internal Standard (Pentachlorobenzene, $100 \mu \mathrm{g} / \mathrm{L}$ ) were obtained from AccuStandard. The Stock solutions were diluted with ethyl acetate to prepare working standards which were later used to prepare calibration standards in the range of $0.1-25 \mu \mathrm{g} / \mathrm{L}$. All solvents used for sample analyses (hexane, ethyl acetate, acetone, toluene, acetonitrile, methanol) were of Pesticide grade.

\section{Analytical quality control}

The quality control includes the analysis of Okinawa Trough sediments (open ocean) as sediment blanks, blanks (Milli Q water), pre-extracted and spiked river water, sediments and plant samples $(10 \mu \mathrm{g} / \mathrm{L})(\mathrm{N}=8)$ and duplicate analysis of samples from each sampling site shows good recoveries as shown in Table 1 . All spiked samples consists of all reagents were exposed to all glassware and equipments, and undergoes through the same extraction procedures were run to check for interference compounds. None of the target compounds were detected. The gas chromatogram of OCPs Standards and samples are shown in Figs. 2 and 3 respectively.

\section{RESULTS}

Numerous studies of OCPs in the environment of Japan have been carried out in different environmental matrices, including plants, biota, soil, sediments and water. The present study have been undertaken in order to provide the preliminary information on the concentration of OCPs in river water, plants and surface sediments from selected rivers in Okinawa Island for the first time and to investigate their contamination level. The detected compounds were Aldrin, $\alpha, \beta, \delta, \gamma-$ BHC, Dieldrin, Heptachlor epoxide (isomer B) and Methoxychlor. The results for the detection of OCPs in water, plants and sediments are shown in Table 2. The values shown in the table indicate the range, mean and standard deviation of concentration during the period of sampling (October 2005-June 2006). The total OCPs concentration for the selected rivers ranged from 0.94 $\mathrm{ng} / \mathrm{L}-231.8 \mathrm{ng} / \mathrm{L}$ (water), 0.006-191.6 ng/g (plants) and $0.001-55.8 \mathrm{ng} / \mathrm{g}$. The total concentration of OCPs in the selected rivers is shown in Fig. 4. The highest concentration of organochlorine pesticides were $94 \mathrm{ng} / \mathrm{L}$ (Aldrin) (Ho) (water), $91 \mathrm{ng} / \mathrm{L}$ ( $\alpha$-BHC) (AJ) (water), 84 ng/L ( $\beta$-BHC) (AJ) (water), $23.5 \mathrm{ng} / \mathrm{L}(\delta$-BHC) $(\mathrm{Ko})$ (water), $60 \mathrm{ng} / \mathrm{L}(\gamma$-BHC) (As) (water), $178.7 \mathrm{ng} / \mathrm{g}(\mathrm{Oku})$ (plant), 38 ng/L (Heptachlor epoxide) (Ko) (water), 56 ng/L (Methoxychlor) (AJ) (water). In Aja River, the highest concentration of OCP was $91 \mathrm{ng} / \mathrm{L}(\alpha-\mathrm{BHC})$ (water) (December 2005), followed by $84 \mathrm{ng} / \mathrm{L}$ ( $\beta$-BHC) (water) (November 2005). The mean concentration of OCP was $103.1 \pm 86.4 \mathrm{ng} / \mathrm{L}$ (water), $11.8 \pm 18.7 \mathrm{ng} / \mathrm{g}$ (plants) and 7.6 $\pm 5.0 \mathrm{ng} / \mathrm{g}$ (sediments). In Asato River, the highest concentration of OCP was $60 \mathrm{ng} / \mathrm{L}(\delta$-BHC) (water) (October 2005), followed by $58.9 \mathrm{ng} / \mathrm{L}$ (Aldrin) (water) (December 2005). The mean concentration of OCP was $87.379 .4 \mathrm{ng} / \mathrm{L}$ (water), $0.11 \pm 0.2$ (ng/g) (plants) and $23.9 \pm 20.5 \mathrm{ng} / \mathrm{g}$ (sediments). For Houtoku River, the highest concentration of OCP was $94 \mathrm{ng} / \mathrm{L}$ (Aldrin) (water) (December 2005), followed by $90 \mathrm{ng} / \mathrm{L}$ (Aldrin) (water) (October 2005). The mean concentration of OCP was $85.377 .8 \mathrm{ng} / \mathrm{L}$ (water), $0.12 \pm 0.09 \mathrm{ng} / \mathrm{g}$ (plants) and $2.6 \pm 2.9 \mathrm{ng} / \mathrm{g}$ (sediments). Aja, Asato and Houtoku Rivers are all located within the residential area. The OCPS from the area maybe washed into these rivers by rainfall. Since OCPS frequently volatilize into the air. Depending on their stability, they can be taken up into the atmosphere and transported long distances. They may then return to the ground through rainfall. For Kokuba River and Okukubi River, both of which runs though Manko Estuary and Okukubi Estuary. In Kokuba River, the highest concentration of OCP was $56 \mathrm{ng} / \mathrm{L}$ (Dieldrin) (water) (November 2005), followed by $40 \mathrm{ng} /$ $\mathrm{L}(\alpha$-BHC) (water) (November 2005). The mean concentration of OCP was $84.9 \pm 62.4 \mathrm{ng} / \mathrm{L}$ (water), 28.1 $\pm 13.5 \mathrm{ng} / \mathrm{g}$ (plants) and $1.9 \pm 1.4 \mathrm{ng} / \mathrm{g}$ (sediments). In addition, the highest concentration of OCPs detected in Okukubi River was 178.7 ng/g (Dieldrin) (plants) (June 2006), followed by $39 \mathrm{ng} / \mathrm{g}$ (Methoxychlor) (June 2006). The mean concentration of OCP was $0.9 \pm 0.2 \mathrm{ng} / \mathrm{L}$ (water), $57.9 \pm 90.9 \mathrm{ng} / \mathrm{g}$ (plants) and $0.6 \pm 0.5 \mathrm{ng} / \mathrm{g}$ (sediments). It is suggested that the sources of these OCPs maybe come from agricultural activities (Okukubi) and commercial and naval ports (Kokuba). The most detected OCP compounds were Aldrin, a-BHC and b-BHC (water), (sediments) and a-BHC and Dieldrin (plants) In 


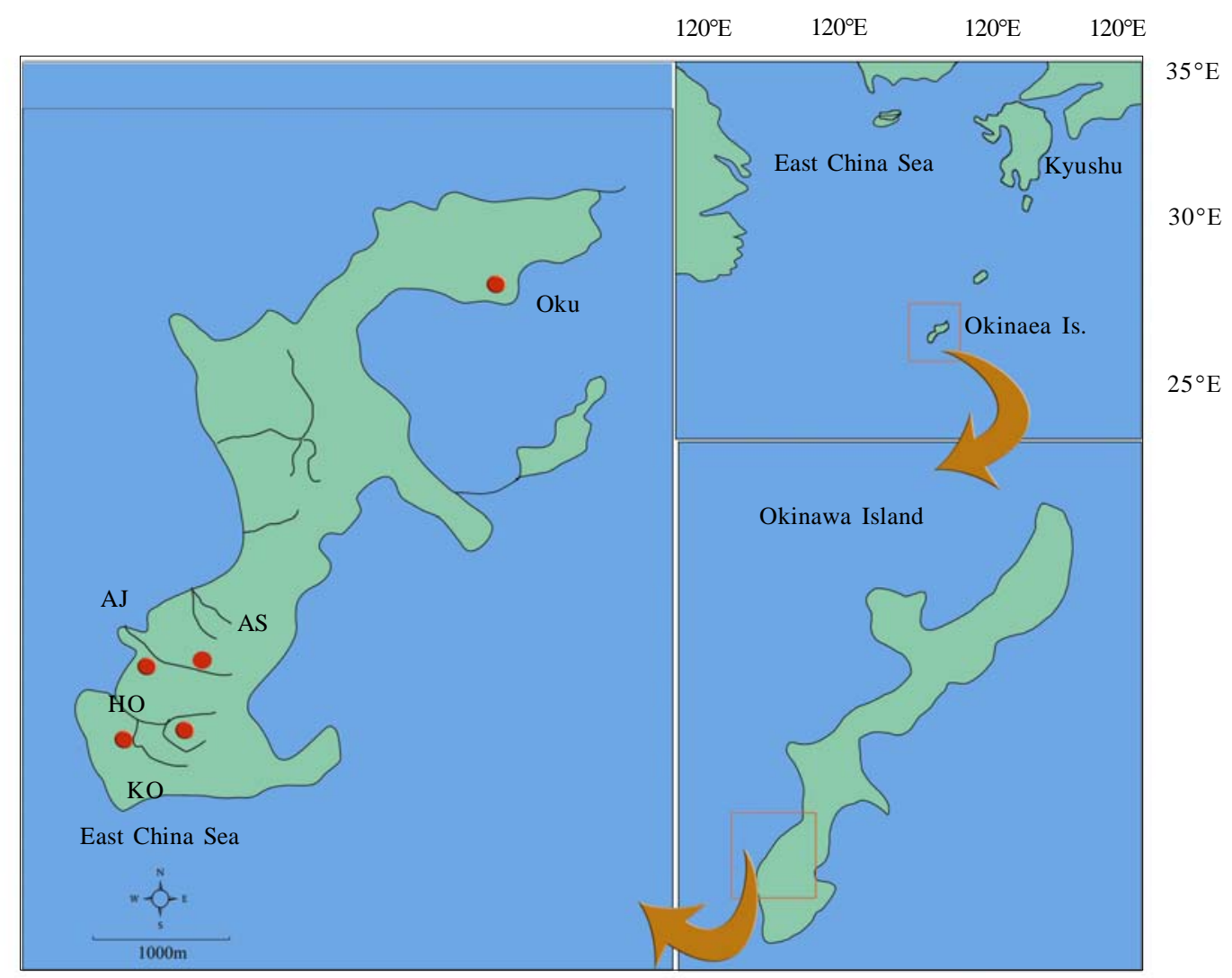

Fig. 1: Map showing sampling locations in Okinawa Island

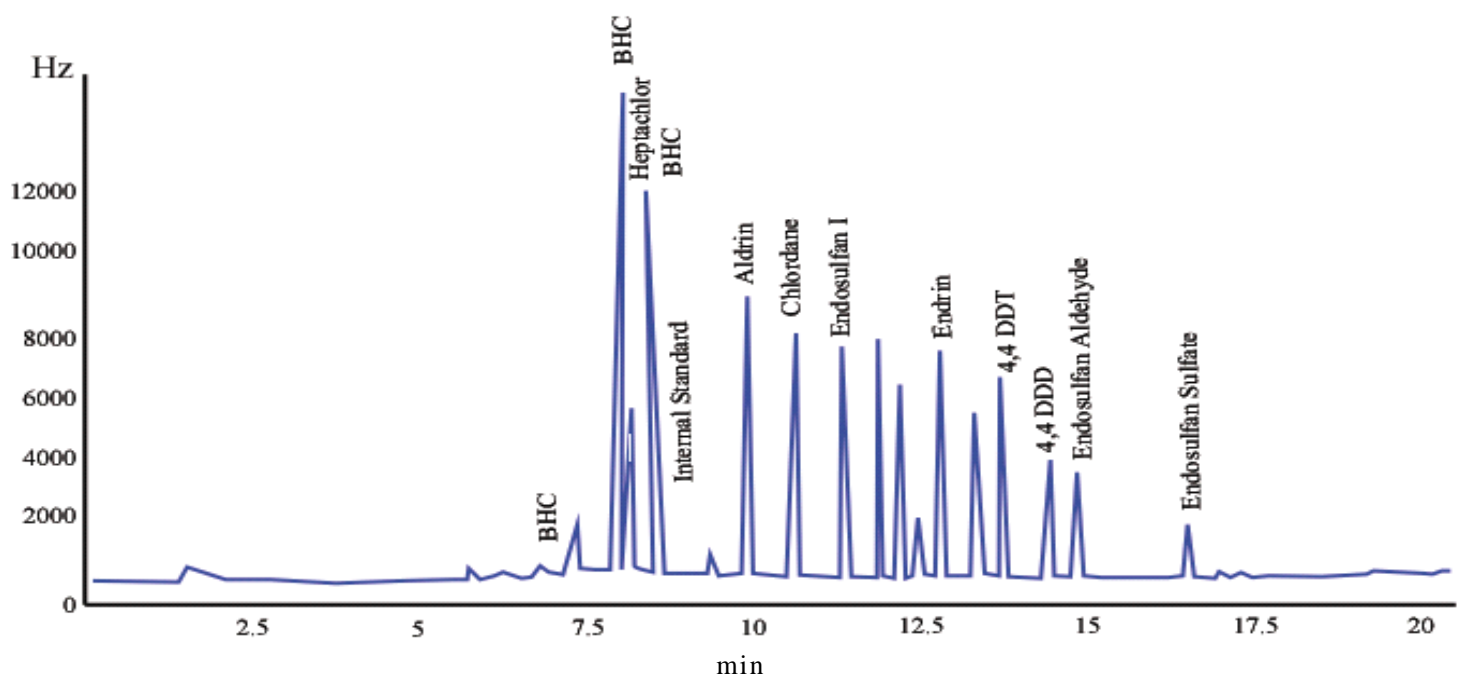

Fig. 2: Gas Chromatogram of OCP standards (19 compounds and internal standard, pentachloronitrobenzene) at $10 \mu \mathrm{g} / \mathrm{L}$ 


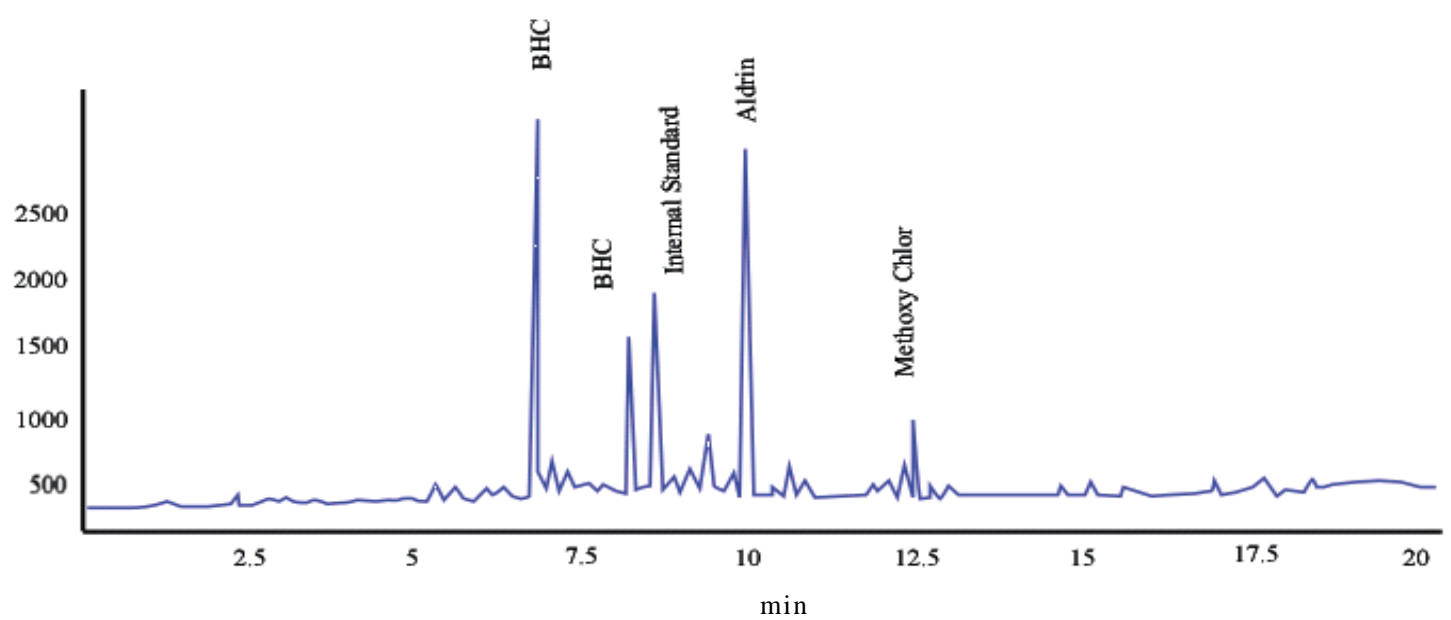

Fig. 3: Gas Chromatogram of water sample from Aja River (January 2006)

Table 1: Mean Recovery (\%), Relative Standard Deviation (RSD) (\%), Limit of Detection (LOD) for OCPs. $(\mathrm{N}=8)$

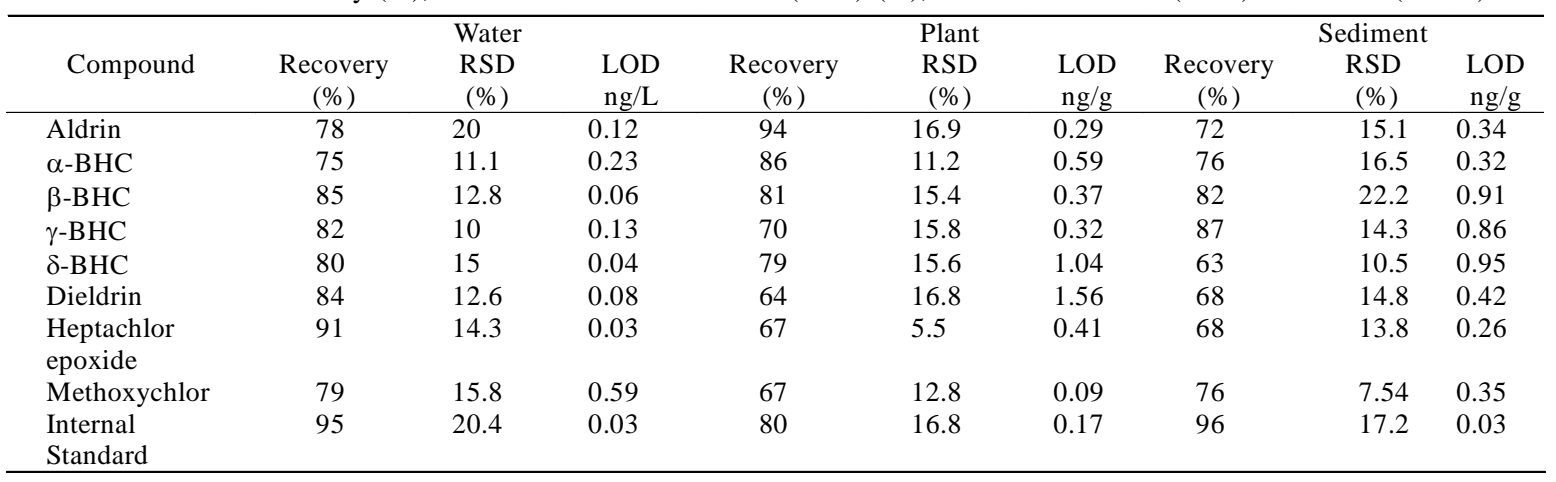

Table 2: OCPs concentrations in water, plant and sediments from the selected rivers in Okinawa

\begin{tabular}{|c|c|c|c|c|c|c|c|c|c|}
\hline Compound & Range & $\begin{array}{c}\text { Water } \\
\text { (ng/L) } \\
\text { Mean }\end{array}$ & SD & Range & $\begin{array}{c}\text { Plant } \\
\text { (ng/g) } \\
\text { Mean }\end{array}$ & SD & Range & $\begin{array}{c}\text { Sediment } \\
\text { (ng/g) } \\
\text { Mean }\end{array}$ & SD \\
\hline$\alpha-\mathrm{BHC}$ & $<\mathrm{LOD}-91$ & 15.9 & 21.4 & ND & ND & ND & $<\mathrm{LOD}-19.8$ & 4.7 & 6.6 \\
\hline$\beta-\mathrm{BHC}$ & $<\mathrm{LOD}-84$ & 19.3 & 20.1 & $<\mathrm{LOD}-0.57$ & 0.2 & 0.3 & $<\mathrm{LOD}-8.9$ & 4.8 & 5.9 \\
\hline$\gamma$-BHC & $<\mathrm{LOD}-60$ & 11.9 & 10.2 & ND & ND & 1.0 & ND & ND & ND \\
\hline Dieldrin & $<\mathrm{LOD}-56$ & 13.4 & 16.1 & $<\mathrm{LOD}-178.7$ & 38.2 & 69.2 & $<\mathrm{LOD}-6.0$ & 2.6 & 1.9 \\
\hline $\begin{array}{l}\text { Heptachlor } \\
\text { epoxide }\end{array}$ & $<\mathrm{LOD}-60$ & 8.90 & 17.1 & ND & ND & ND & ND & ND & ND \\
\hline Methoxychlor & $<\mathrm{LOD}-56$ & 8.90 & 15.9 & $<\mathrm{LOD}-39.02$ & 19.2 & 17.8 & $<\mathrm{LOD}-0.6$ & 0.4 & 0.3 \\
\hline $\begin{array}{l}\text { Internal } \\
\text { Standard }\end{array}$ & $<\mathrm{LOD}-94$ & 19.1 & 27.3 & $<\mathrm{LOD}-33.4$ & 16.7 & 23.6 & $<\mathrm{LOD}-3.0$ & 1.4 & 1.5 \\
\hline
\end{tabular}

<LOD: Less than the limit of detection

ND: Not detected 
(a)

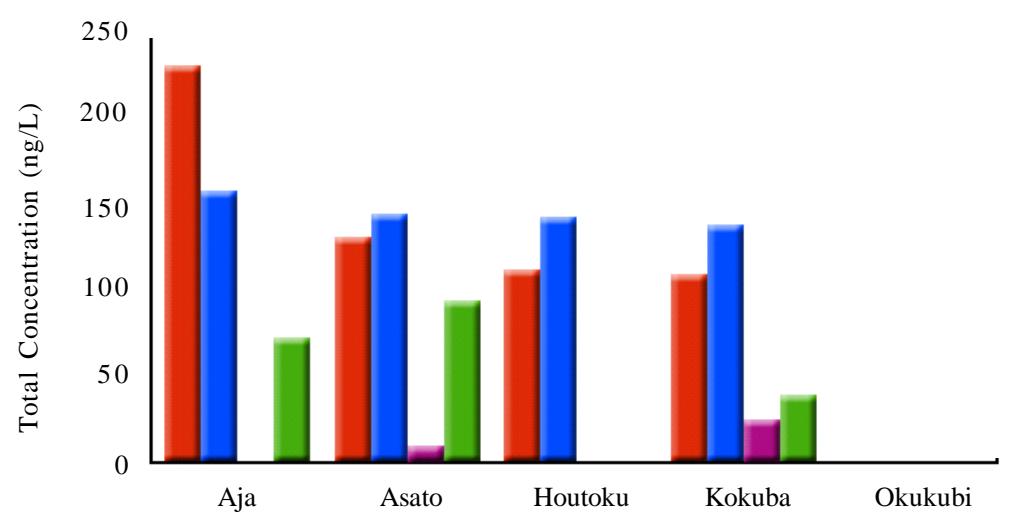

(b)

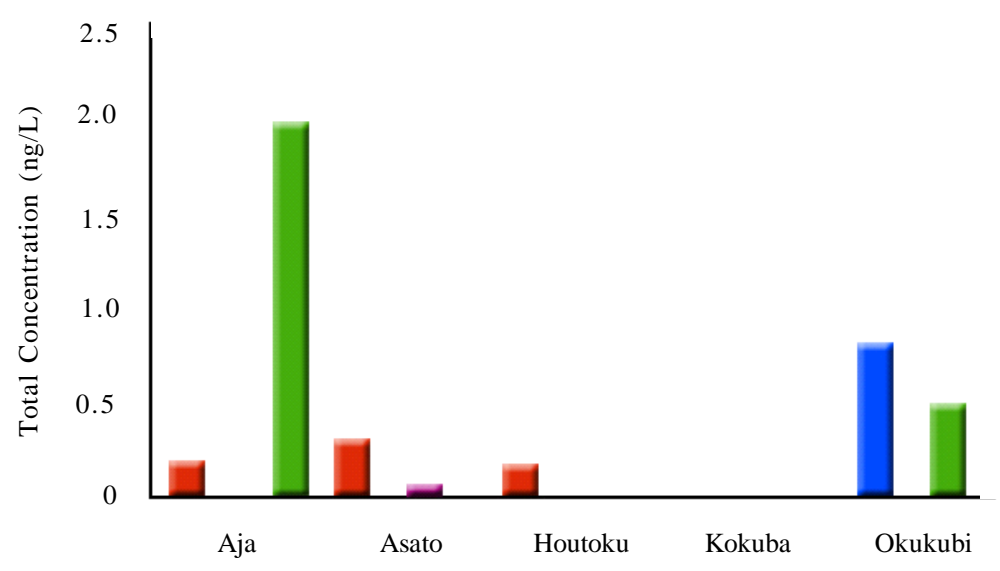

(c)

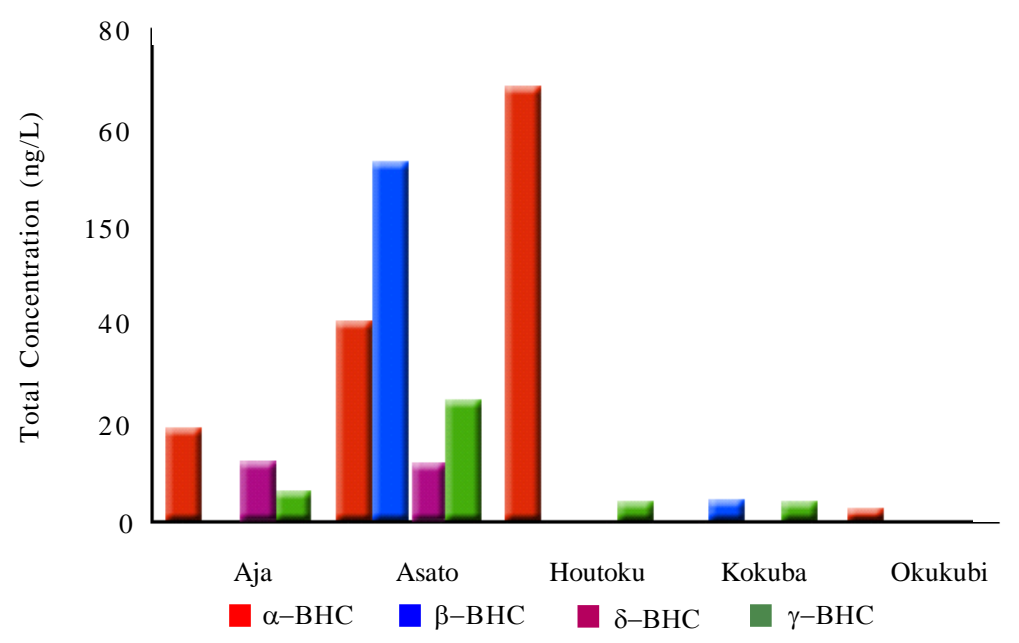


(d)

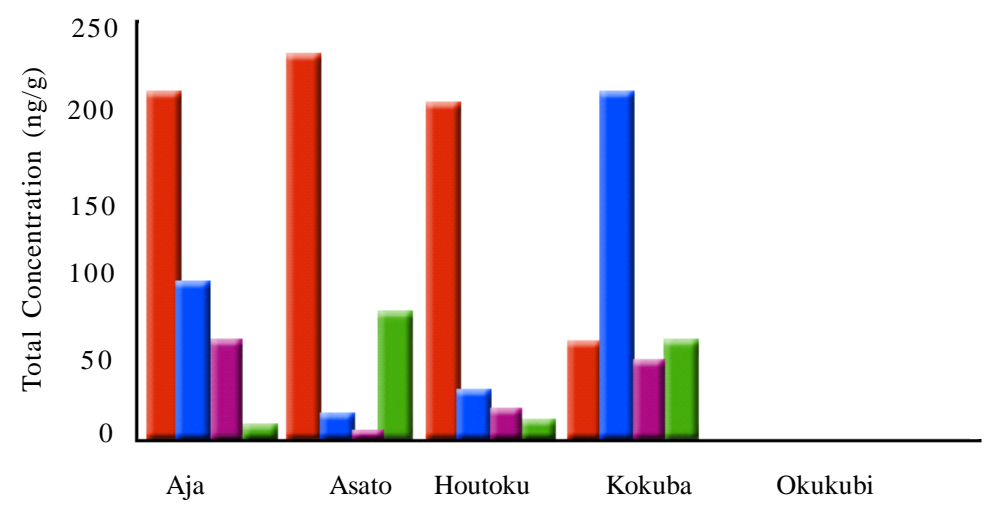

(e)

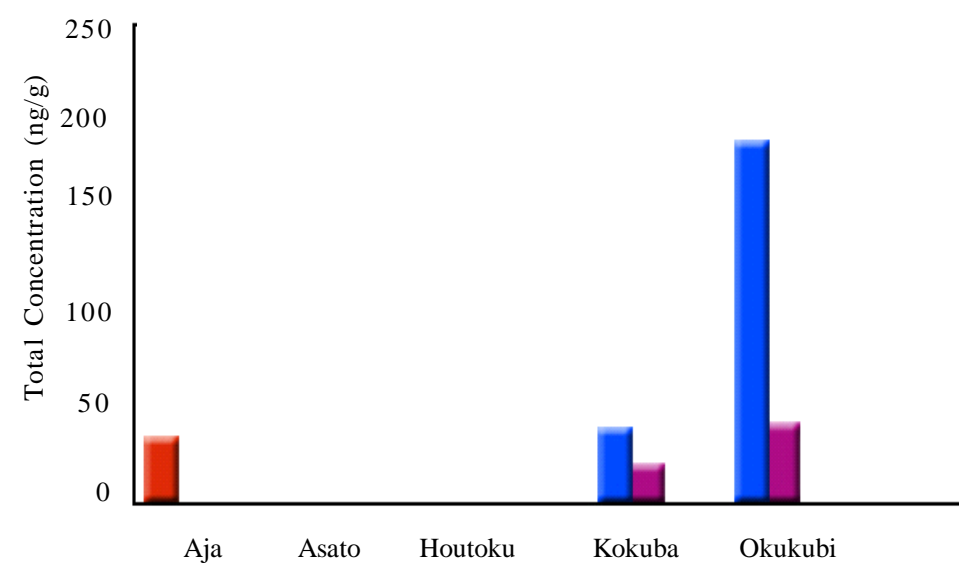

(f)

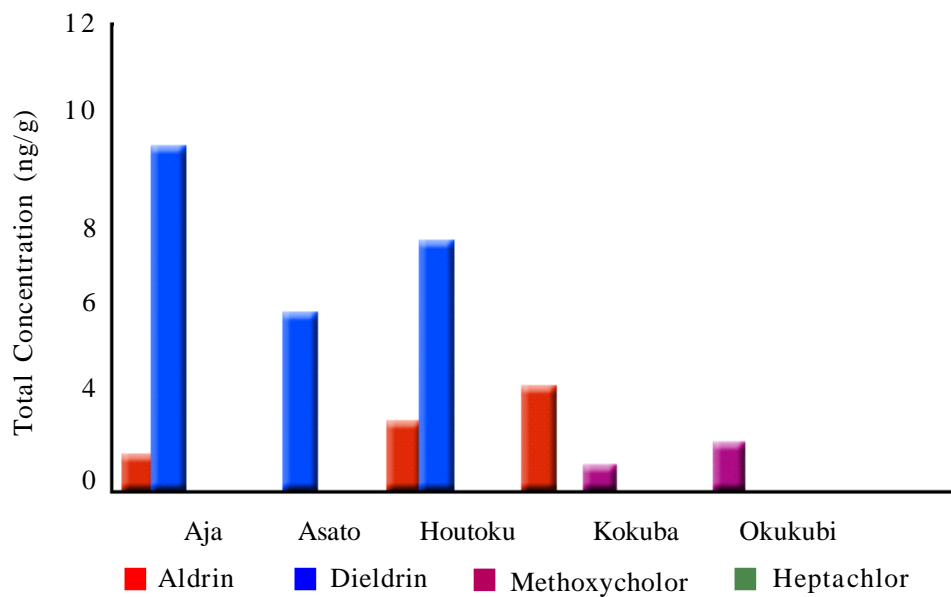

Fig. 4: Total Concentrations of BHCs and other chlorinated pesticides at different sampling locations. a and d. water samples, b and e. plant samples and c and f. surface sediment samples (October 2005 - June 2006) 
some samples, the concentration of OCPs was higher 178.7ngg ${ }^{-1}$ (Dieldrin) (plants) (Okukubi) (June 2006) than the qualitative target level set by the Japanese Ministry of Environment and WHO.

\section{DISCUSSION AND CONCLUSION}

This study provides the preliminary information on the current contamination status of the selected rivers in Okinawa Island. The OCPs which have been detected were Aldrin, Dieldrin, $\alpha, \beta, \delta, \gamma$-BHC, Heptachlor epoxide (isomer B) and Methoxychlor. In some sites, the concentration detected were higher than the permissible level set by the Japanese Ministry of Health and Environment and WHO especially for the cases of Aldrin, $\alpha$-BHC and $\beta$-BHC (water), (sediments), $\alpha$-BHC and Dieldrin (plants).The possible sources of these OCP compounds are from residential areas (Aja, Asato, and Houtoku), commercial and naval ports (Kokuba) and agricultural activities (Okukubi). The OCPs may be washed into rivers by rainfall. Surface water, plants and sediments may receive OCP sprays either intentionally (e.g. in order to control insects and water weeds) or unintentionally (e.g. when crops are sprayed near rivers or streams). These compounds are very stable substances and their long residence time; there is a great interest in examining the pollution they cause.

\section{ACKNOWLEDGEMENTS}

This Study was funded by the grant from the Ministry of Education, Culture, Sports, Science and Technology of Japan and the $21^{\text {st. }}$ Century COE Program of the University of the Ryukyus, Japan. The authors are indebted to Mr. Toshihiko Miyagi, Chief of Water Pollution of Okinawa Prefecture Institute of Health and Environment for the provision of the current detailed of OCPs in Okinawa. The authors also wish to thank Dean Seuoti, Michihiro Ito and Naumih Mwende Noah for the help during the sampling.

\section{REFERENCES}

Awofolu, R.P., Fatoki, O.S., (2003). Levels of Cd, Hg and Zn in. some surface waters from the Eastern Cape Province, South. Africa. Water SA, 29 (4), 375-380

California Department of Food and Agriculture, (1999). Center of Analytical Chemistry. Determination of Bifenthrin in surface water by GC-ECD, Method No. 7 .

Chanel, I., Chang, I., (2000). Analysis of OCPs and PCB Congener with Agilent 6890 Micro-ECD, Gas Chromat. Agilent Technologies Inc.

Doong, R.A, Sun, Y.C, Liao, P.L, Peng, C.K., Wu, S.C., (2000). The distribution and fate of organochlorine pesticide residues in sediments from the selected rivers in Taiwan. Chemo., 48, 237-246.

Forget, J., Solomon, K.R., Ritter, L., (2001). A review of selected persistent organic pollutants; DDT, Aldrin, Dieldrin, Endrin, Chlordane, Heptachlor, Hexachloro-benzene, Mirex, Toxaphene, Polychlorinated biphenyls, Dioxins and Furans; IPCS report PCS/95.39.

Fushiwaki, Y., Urano, K., (2001). Adsoprtion of pesticides and then biodegraded products on clay minerals and soils. J. Health Sci., 47 (4), 429-432.

Golfinopoulos, S.K., Anastacia, N.D., Lekkas, T., Vagi, M.C., (2002). Organochlorine pesticides in the surface waters of Northern Greece. Chemo, 50, 507-516.

Hung, D.Q., Thiemann, Q., (2002). Contamination by selected chlorinated pesticides in surface waters in Hanoi, Vietnam. Chemo., 47, 357-367.

Japan Ministry of Environment. Environmental Quality Standards for water pollution, available at: http:// www.env.go.jp/en/water/wq/wp.html

Kang, Y.H., Gonz, Y., Li, G.G., (2001). The Study of VOCs in Guanting reservoir and Yonginghe River. China. Acta Soci., 21 (3), 338-343.

Kennedy, I.R., Ahmad, N., Beasley, H., Chapman, J., Hobbs, J., Simpson, B. and Woods, N., (1998). Quality assurance in pesticide sampling and analysis. LWRRDC Occasional Paper No 14/98. Land \& Water Resour. Res. \& Development Corp., Canberra, Australia.

Laabs, V., Amelung, W., Pinto, A.A., Wantzen, M., C.J da Silva and Zech, W., (2002). Pesticides in surface waters, sediments and rainfall of the Northeastern Pantanal Basin, Brazil. J. Env. Qual., 31,1636-1648.

Miliadis, G.E., (1993). Gas chromatographic determination of pesticide in natural waters of Greece. Bull. Environ. Contaminat. Toxic., 50, 247.

Nakai, K., Nakamura, T., Susuki, K., Oka, T., Okamuri, J., Sugawara, N., Saitoh, Y., Onba, T., Kameo, S., Satoh, H., (2004). Organochlorine pesticides residues in human breast milk and placenta in Tohoku, Japan. 66.

Okinawa Prefecture Summary Basic Plan, (2002). Okinawa Prefecture Institute of Health and Environment.

Primbs, T., (2004). EPA STAR Graduate Fellowship Conference, POPs and other Anthropogenic SOCs in Eurasian Air Masses Measured at Rural site in Okinawa, Japan.

Quantitation Methods in GC, (2001). GC Education

Racke, K.D., Skidmore, M.W., Hamilton, D.J., Unsworth, J.B., Miyamoto, J., Cohen, S.Z., (1997). Pesticide fate in tropical soils (technical report). Pure Appli. Chem., 69, 1349-1371

Report on Environment Survey and Monitoring of Chemicals in FY 2004. Ministry of the Environment, Government of Japan, 2005.

Tanabe, S., Iwata, H., Tatsukawa, R., (1994). Global contamination of persistent organochlorine and their ecotoxicological impact on marine mammals, Sci. Total Environ., 154, 163-177.

World Health Organization (WHO), (2005). Guideline Values. Available at: http://www.who.int/en/

Yoshida, S., Taguchi, S., Tanaka, Y., Hori, S., Occurrence of an OCP Synergist S-421 in fish and shellfish. Osaka Prefecture Institute of Public Health.

Zhang, Z., Hong, H., Zhou, J., Wang, X.J., (2002). Transport and fate of organochlorine pesticides in the River Wucuan. Southeast China. Environ. Monit, 4, 435-441. 


\section{AUTHOR (S) BIOSKETCHES}

Imo, T.S., B.Sc. in mathematics, M.Sc. in Chemistry, Graduate School of Engineering and Science, University of the Ryukyus, Senbaru 1, Nishihara-cho, Okinawa 903-0213, Japan.

Email: k058557@eve.u-ryukyu.ac.jp

Sheikh, M.A., B.Sc., M.Sc. in chemistry, Department of Chemistry, Biology and Marine Science, Faculty of Science, University of the Ryukyus, 1 Senbaru, Nishihara-Town, Okinawa 903-0213, Japan.

Email: sheikhmali2003@yahoo.com

Hirosawa, E., B.Sc. in chemistry, Graduate School of Engineering and Science, University of the Ryukyus, Senbaru 1, Nishihara-cho, Okinawa 903-0213, Japan. Email: k058557@eve.u-ryukyu.ac.jp

Oomori, T., Professor in chemistry and oceanography, Department of Chemistry, Faculty of Science, University of the Ryukyus, Senbaru 1, Nishihara-cho, Okinawa 903-0213, Japan.

Email: oomori@eve.u-ryukyu.ac.jp

Tamaki, F., M.Sc. in chemistry, Okinawa Prefectural Institute of Health and Environment, Water Pollution Section, 2085 Ozato, Ozato-son, Okinawa 901-1202, Japan.

Email: tamaki@gravity.phys.waseda.ac.jp

This article should be referenced as follows:

Imo, T.S., Sheikh, M.A., Hirosawa, E., Oomori, T., Tamaki, F., (2007). Contamination by organochlorine

pesticides from rivers. Int. J. Environ. Sci. Tech., 4 (1), 1-9 . 